DOI: $\underline{10.17805 / g g z .2020 .2 .6}$

\title{
Татуировка. Психологический анализ
}

\author{
Л. А. Иванова
}

Институт косметологии, эстетической медицины и визажного искусства - Дом русской косметики, г. Москва,

\section{Д. Д. Владимирова}

Московский педагогический государственныий университет

В статье анализируются и формулируются проблемы психологического анализа татуировок и людей, обладающих ими. Среди них выделяется проблема повыщения спроса на татуировку и влияния татуировки на внутреннее психологическое состояние человека. Цель статьи - систематизировать имеющуюся информацию и накопленный материал по татуировкам и провести психологический анализ людей обладающих ими. Методологию исследования составляют анализ и обобщение работ зарубежных и отечественных ученых.

На основании проведенного исследования сформулированы и проанализированы психологические особенности людей, обладающих татуировками, а именно: систематизированы представления о мотивах нанесения татуировки на тело, выявлено психологическое воздействие татуировки на психологическое состояние человека, представлены характерные черты людей, выбравиих за основу татуировки определенную фигуру и ивет.

Как отмечают авторы, чаще всего люди решаются на нанесение татуировки на свое тело ввиду погони за современной модой, а также для выделения себя из толпы, стремясь стать уникальным, привлечь к себе больше внимания со стороны окружающих. Однако при выборе того или иного рисунка, а также места его нанесения люди руководствуются определенными мотивами и принципами. Так, зная психологические особенности татуировки, возможно узнать о человеке достаточно много информации.

Ключевые слова: татуировка; психологический анализ; характерные черты людей; нанесение татуировки; мотивачия; тату-искусство

\section{Tattoo. A Psychological Analysis}

\author{
L. A. Ivanova
}

Institute of Cosmetology, Aesthetic Medicine and Visage Art -

House of Russian Cosmetics, Moscow,

D. D. Vladimirova

Moscow State Pedagogical University 
The article analyzes and formulates the issues of psychological analysis of tattoos and people who possess them. The one that stands out is the problem of increasing demand for tattooing and the effect of the tattoo on the person's internal psychological state. The objective of the article is to systematize the available information and accumulated materials on tattoos, and to conduct a psychological analysis of people who have them. The research methodology comprises the analysis and generalization of research works by foreign and Russian authors.

Based on the study, psychological characteristics of people with tattoos are presented and analyzed, namely: perceptions of the motives for tattooing on the body are systematized, the psychological effect of the tattoo on the internal state of a person is revealed, the characteristic features of people who choose a specific figure and color for the inked tattoo are presented.

According to the authors, people usually decide to draw a tattoo on their body due to the pursuit of modern fashion, as well as to distinguish themselves from the crowd, desiring to be unique and to attract more attention from other people. However, when choosing one or another drawing, as well as the place of tattooing, people are guided by certain motives and principles. So, knowing the psychological characteristics of the tattoo, it is possible to find a fair bit of information about the person.

Keywords: tattoo; psychological analysis; characteristic features of people; tattooing on the body; motivation; tattoo art

\section{ВВЕДЕНИЕ}

Татуировки наносили на тело во все времена, и это никак не связано с модой. На сегодняшний день увеличился спрос на татуировки ввиду повышения уровня и качества нанесения татуировок. Западные страны прошли через это давно, однако в России татуировка всегда считалась чем-то особенным, неким показателем собственной значимости, определенным вызовом общественным нормам, так как в нашей стране в обществе сложились определенные стереотипы о том, что рисунок на теле преимущественно относится к криминальной среде. Когда татуировка начала распространяться в обществе, важно было наличие самого рисунка. Теперь важны не только рисунок, но и качество нанесения татуировки, и профессионализм мастера. Однако при выборе того или иного рисунка, а также места его нанесения, люди руководствуются определенными мотивами и принципами. В нашей статье мы рассмотрим психологические особенности людей, обладающих татуировками, а также проведем психологический анализ накопленной информации и материалов по татуировкам.

В настоящее время татуировка воспринимается среди людей как что-то молодежное и современное. При этом история татуировки насчитывает не 
одну тысячу лет. В древности она являлась одним из видов изобразительного искусства. Считалось, что люди, имеющие татуировкой на теле, относятся к особой группе населения. В средневековой Европе данный вид искусства не получил дальнейшего развития, поскольку был запрещен церковью. Такая ситуация сохранялась вплоть до Нового времени (Atkinson, 2004: 126).

Перелом в развитии тату-искусства пришелся на 60-е гг. ХХ в., когда начали зарождаться и развиваться контркультурные молодежные движения. Этот период знаменуется началом формирования современных стилей татуискусства, в основе которых лежали древневосточные и европейские стили (Скорова, б/д: Электронный ресурс). Немаловажной датой в развитии татуировки является 1981 г. Именно в этом году впервые появляется электрическая машинка для нанесения татуировки на тело.

Современное время характеризуется не только широким распространением татуировки, но также и появлением косметологических направлений, таких как татуаж и перманентный макияж, ставшими очень популярными среди современных женщин, так как обладает большими достоинствами и преимуществами по сравнению с обычным макияжем (Caplan, 2002: 406).

\section{РЕЗУЛЬТАТЫ ИССЛЕДОВАНИЯ}

Татуирование тела, также как и украшения прической, макияжем, одеждой, - это способ самовыражения путем привлечения к себе внимания окружающих. Статистика показывает, что чаще всего татуировки наносят на свое тело люди, имеющие высокие амбиции, возможно, именно поэтому среду людей с татуировками на теле много артистов, художников и музыкантов (Овсянникова, 2017).

Татуировка, являющаяся одним из видов искусства, способна психологически воздействовать на внутреннее состояние человека. Обоснованием этому служит тот факт, что, решив сделать татуировку на своем теле, человек должен осознавать истинную причину, натолкнувшую его на этот шаг, и такая причина является мотивацией, которая есть у любого, но у каждого она своя.

Рассматривая психологическую сторону татуировки, мы можем утверждать, что человек является существом социальным, и посредством свой внешности оказывает определенное воздействие на окружающих (Шнырева, 2009).

Человек, окончательно решивший нанести на свое тело татуировку, должен знать и руководствоваться всеми аспектами татуирования. Рассматривая психологический аспект татуировки, необходимо отметить, что он непосредственно взаимосвязан с побудительным мотивом подражания или ложными эстетическими побуждениями. Однако татуировка, сделанная с полным пониманием ее сути и назначения и на основе осознанного выбора, может стать 
своеобразной визитной карточкой человека, тем самым закрепить за ним определенный индивидуальный имидж. Татуировка заключает в себе активный смысл, своего рода показатель характера человека (Филатова, 2013: 22).

Так, решив сделать на своем теле татуировку, каждый человек руководствуется своим определенным мотивом. Мы выделим и рассмотрим основные из них.

Самой распространенной мотивацией является самовыражение, которое основано на стремлении быть неординарным и желании показаться остальным более модным и современным. Такой мотивацией руководствуются в основном в молодом возрасте, что впоследствии может привести к тому, что татуировка надоедает, и ее обладатель желает ее свести (Федорова, Жукова, 2020: 221).

Второй наиболее распространенной мотивацией нанесения татуировки на тело является убеждение, которое заключается в стремлении доказать окружающим, что человек принадлежит к определенной группе людей, а также самому себе, что он предан своей цели и идеи. Так, из-за убеждения люди наносят на свое тело изображения эмблем организаций, в которых они состоят, религиозные символы, флаги родины и т. д. (Naudé, Jordaan, Bergh, 2019: 178).

Однако современный психолог и преподаватель Массачусетского университета в Амхерсте, автор многих книг по психологии Кирби Фарррел полагает, что о сильной зависимости, в том числе к татуировкам, можно говорить лишь в том случае, когда человек испытывает труднопреодолимое желание, мешающее ему вести нормальную жизнь. При этом татуировка первостепенно заключает в себе искусство. Как и любое искусство, от вязания крючком до литературного творчества, татуировка привносит в нашу жизнь нечто прекрасное и осмысленное (Farrell, 2015). Посредством татуировки человек привлекает к себе внимание окружающих, за счет чего увеличивается его самооценка, и как следствие человек ощущает определенную гордость за то, что делится с окружающими такой красотой.

Еще одной распространенной мотивацией, занимающей третье место, является мотивация, основанная на комплексе неполноценности или чувстве собственной незащищенности или слабости. Такая мотивация подталкивает людей на нанесение татуировок с агрессивным содержанием, устрашающими животными или мифологическими существами. За счет такой татуировки человек способен поднять свою самооценку, попытаться показать окружающим, что он не настолько слаб духом, как может показаться на первый взгляд (Воробьева, 2016ab, 2018). Однако не стоит делать поспешные выводы, увидев человека с татуировкой в виде тигра, льва или дракона. При анализе татуировок всегда необходимо учитывать множество факторов. Например, рычащий лев 
или тигр могут означать принадлежность к той или иной спортивной команде, представляя символ организации.

Существует еще такой вид мотивации, как косметическая. Она вызвана желанием исправить внешние недостатки своего тела (например, старые татуировки, которые больше не хочется носить на своем теле), спрятать шрамы и пигментные пятна и даже скрыть асимметрию тела (Бекетова, 2016: 12).

Согласно данным американского журнала Psychology Today, татуировка заключает в себе одну из форм самосовершенствования. Люди наносят татуировки на свое тело, чтобы украсить и улучшить его. Это можно сравнить с соблюдением диеты для похудения или пластической операцией, которая делается для того, чтобы выглядеть и чувствовать себя лучше, чем прежде (Neuhaus, 2018). Так, человек, сделавший на своем теле рисунок, полагает, что теперь он выглядит намного лучше и привлекательнее, и как следствие окружающие будут чаще его замечать. Таким образом, татуировка как произведение искусства становится частью тела ее владельца.

В криминальном мире также распространена статусная мотивация нанесения татуировки на тело, которая свидетельствует об определенном ранге, положении, а порой может служить и документом человека. Однако не все люди, имеющие татуировки, каким бы ни был рисунок, принадлежат к преступному миру.

В последнее время получило распространение нанесение татуировок военнослужащими. Так, молодые люди, вновь прибывшие на службу, наносят знак или эмблему определенных войск в виде татуировки, и это воспринимается как своеобразный обряд посвящения. Согласно исследованию, опубликованном в англоязычном интернет-блоге Lifehacker, примерно 36 \% военнослужащих в США имеют на своем теле татуировку (Allan, 2016: Электронный реcypc).

В определенных случаях и ситуациях возможно охарактеризовать личность человека по рисунку на его теле. Например, человек может быть скромным, тихим и спокойным, но при этом на его теле присутствует татуировка, выражающая определенную агрессию. Так, мы можем предположить, что данный человек пытается агрессивными изображениями компенсировать свою незащищенность и слабость. Однако не стоит забывать о том, что, анализируя смысл татуировки, необходимо учитывать множество факторов, а также незначительные особенности ее носителя (Новгородова, 2017: 537).

По мнению доктора К. Фаррелла, татуировки есть «пассивная агрессивность». Аргументирует он это тем, что, нанося жестокие татуировки на тело, человек тем самым выражает определенную агрессию и протест в отношении общества. Это выражается за счет внутреннего гнева человека. Его мнение подтверждается результатами исследований, проведенных профессором 
Вирена Свами из университета Англия Раскин. Они показали, что чем больше у человека на теле татуировок, тем он злее. Так, Свами пришел к выводу, что люди с несколькими татуировками на теле склонны быть более жестокими и агрессивными (Farrell, 2015).

Исследования американского доктора психологических наук Виниты Мехты показали определенные сходства личных качеств людей, обладающих татуировкой на своем теле. Большинство людей хотят за счет татуировок почувствовать себя уникальными. Так, исследование показало, что женщины с заниженной самооценкой, которые испытывают определенные беспокойства в жизни, после того, как делают татуировку, неожиданно становятся более счастливыми и уверенными в себе, чувствуют прилив энергии. Но по истечению примерно одного месяца они начинают испытывать беспокойство по поводу нанесенной татуировки и начинают задумываться о принятом решении. Если говорить о мужчинах, то здесь все наоборот: они в меньшей степени беспокоятся и сожалеют о содеянном. Согласно выводам этого же исследования, женщины чаще сводят татуировки, нежели мужчины (Mehta, 2018).

Проблема татуировок, как и любого искусства, заключается в несовершенстве, и его очарование не бесконечно. Спустя определенное время татуировка становится привычной как для ее владельца, так и для окружающих (Degelman, Price, 2002). Помимо этого, меняется и мода. Например, в один год было модно рисовать на теле иероглифы, а в другом получила распространение мода на цветы.

В погоне за модой и в стремлении вновь почувствовать радость от татуировки человек выбирает самый простой способ - сделать новую татуировку, и так может происходить до тех пор, пока не останется свободного места на теле. Такого рода зависимость возникает у людей, воспринимающих красоту как нечто ощутимое, а не как душевное состояние. Они чаще поддаются влиянию мнения не только окружающих людей, но и других внешних факторов (Saleh, 2016).

Некоторые люди, стремясь выделиться из толпы, хотят сделать татуировку на своем теле, но не знают какую. Так, психологами придуман и составлен тест, определяющий наиболее подходящую татуировку для конкретного человека. Тест выглядит следующим образом:

В иелом композичия любой татуировки заключает в себе ту или иную геометрическую фигуру. Треугольник схож с лилией; молния тяготеет к зигзагу, змея, свернутая в клубочек - круг и т. д.

Выберите одну из пяти предложенных фигур, которая наиболее Вам нравится: круг, квадрат, треугольник, прямоугольник, круг, зигзаг. Ниже представлены характерные черты людей, выбравших определенную фигуру. 
Квадрат - символизирует решительного человека, стремящегося довести начатое дело до конца. Человек, выбравший фигуру квадрата, обладает такими личностными качествами как усердие, трудолюбие и упорство. Идеалом Квадрата служит распланированная и предсказуемая жизнь, без неожиданных “сюрпризов” и изменений привычного хода событий.

Прямоугольник - говорит об определенной неудовлетворенности образом жизни, который ведет человек. Ввиду чего данный человек занят поиском лучшего положения в жизни. Ведущчие личностные качества Прямоугольника это - смелость, проявление интереса ко всему происходящему вокруг и любознательность.

Круг обычно символизирует солнще, часы, луну и др. Круг является самой доброжелательной фигурой. Данная фигура означает способность ощущать чужие радости и чувствовать чужую боль как собственную. Люди, выбравиие круг, характеризуются особой чувствительностью и эмочиональностью, способностью сопережсивать и сочувствовать окружающим.

Треугольник символизирует лидерство. Характерными чертами личности, выбравшей треугольник, являются энергичность, сила духа, неудержимость. Данные люди предпочитают ставить перед собой ясные и конкретные цуели, а главное их достигать, при этом избегая возможных конфликтов.

Зигзаг символизирует творческих людей. Рисунки в виде зигзага обычно выглядят в виде молнии или зубов животных. Зигзагам свойственно комбинировать различные идеи и на основе их создавать что-то новое, свое, оригинальное. Фигура зигзага является самой возбудимой, восторженной и экзальтированной из всех пяти (Шапарь, 2016).

С точки зрения психологии, важен также не только сам рисунок, но цвет нанесенной татуировки. Поэтому, выбирая тот или иной цвет, необходимо знать, что цвет татуировки влияет на внутреннее самочувствие человека. Анализ данных хромотерапии, метода лечения цветом, показывает, что цвет может оказывать воздействие на внутреннее самочувствие человека, например, на сердцебиение, частоту дыхания, артериальное давление, скорость реакций и др. Также важным является тот факт, что правильно подобранный цвет татуировки способен улучшить память и внимание примерно на 65 \% (Борохов, 2011: 26; см. также: Борохов, 2018).

Швейцарский психолог, создатель психологического теста, определяющего эмоциональное состояние человека, Макс Люшер точно отмечает, что, предпочитая или отвергая определенные цвета, человек предстает таким, какой есть на самом деле, а не каким пытается казаться, так как цветовой выбор не может лгать. По статистике самым распространенным цветом татуировки является черный цвет, его предпочитают 78 \% людей, на втором месте 
красный цвет - 5 \%, третье место делят сразу несколько цветов: зеленый, синий и коричневый - 4 \%. Такие цвета как белый, фиолетовый и розовый меньше всего используются при нанесении татуировки.

Черный цвет является классическим в мире татуировок. Его применяют при нанесении контура, теней, а также как основной цвет татуировки.

Красный цвет является очень эмоциональным, заключает в себе энергию и способен поднять человеку настроение. Красный цвет в татуировке говорит о том, что ее носитель - уверенный в себе, сильный духом и полный энергией человек. Однако данный цвет способен усилить нервное напряжение. Поэтому при нанесении татуировки красный цвет необходимо использовать с большой аккуратностью и желательно в местах, малодоступных всеобщему обозрению. Также красный цвет зачастую ассоциируется с кровью как в хорошем, так и плохом смысле.

Желтый цвет является броским и игривым. Если его использовать умеренно, то он помогает снять напряжение, стимулирует мышление и творчество. При переизбытке желтый цвет вызывает тревогу и агрессию. При нанесении татуировки его лучше использовать в дополнение к другим цветам.

Синий цвет символизирует цвет моря и неба. Он обладает успокаивающими свойствами, создает ощущение комфорта и расслабленности. Данный цвет означает стабильность в жизни. Также синий цвет обладает свойствами подавления аппетита, так как в природе все синее несъедобное.

Зеленый цвет ассоциируется с легкостью и безопасностью, а также создает некую деловую атмосферу. Зеленый цвет в татуировках говорит о надежности и стабильности.

Фиолетовый цвет связывают с мудростью, утонченностью и благородством. Данный цвет предпочитают интроверты, люди, хорошо ориентирующиеся во внутреннем пространстве своей души. Фиолетовый цвет вызывает доверие и снижает уровень возбужденности (Люшер, 2003: 115).

Оказывая определенное психологическое влияние на внутреннее состояние человека, наносимые татуировки можно разделить на несколько групп:

1. психологические;

2. украшающие;

3. идейные;

4. профессиональные (Broussard, Harton, 2017).

При этом чаще всего татуировку на теле человека невозможно отнести только к одной определенной группе, обычно она может обладать признаками двух или трех групп. 


\section{ЗАКЛЮЧЕНИЕ}

Таким образом, в ходе нашего исследования был выявлен ряд психологических особенностей людей с татуировками: систематизированы представления о мотивах нанесения татуировки, охарактеризовано психологическое воздействие татуировки на внутреннее состояние человека, представлены характерные особенности людей, выбравших за основу наносимой татуировки определенную фигуру и цвет.

Чаще всего люди решаются на нанесение татуировки из-за стремления угнаться за современной модой, а также для того, чтобы выделиться из «серой массы», стать «уникальными» и ни на кого не похожими, желая привлечь к себе больше внимания со стороны окружающих.

\section{СПИСОК ЛИТЕРАТУРЫ}

Бекетова, Е. С. (2016) Выявление личностной проблематики субъекта средствами глубинно-психологического анализа татуировок // Гуманитарнопедагогическое образование. Т. 2. № 2. С. 10-15.

Борохов, А. Д. (2011) Значение татуировок в диагностике психических и поведенческих расстройств // Медицинская сестра. № 7. С. 24-32.

Борохов, А. Д. (2018) Многоосевая классификация татуировок для интегральной оценки проявлений психопатологии личности носителя. Часть 2 // Медицинская психология в России. Т. 10. № 3 (50). С. 10. DOI: 10.24411/2219$\underline{8245-2018-13100}$

Воробьева, Е. С. (2016а) Татуирование как объект социологического исследования [Электронный ресурс] // Журнал социологии и социальной антропологии. Т. 19. № 3. С. 148-161. URL: https://cyberleninka.ru/article/n/tatuirovanie-kak-obekt-sotsiologicheskogo-issledovaniya (дата обращения: 21.02.2020).

Воробьева, Е. С. (2016b) Формирование мотивации к татуированию как механизм конструирования идентичности [Электронный ресурс] // Теория и практика общественного развития. № 6. URL: http://teoria-practica.ru/rus/files/ arhiv zhurnala/2016/6/sociology/vorobiyova.pdf [архивировано в WaybackMachine] (дата обращения: 21.02.2020).

Воробьева, Е. С. (2018) О чем рассказывает татуированное тело: гендерный аспект в опыте визуальной социологии // Интеракция. Интервью. Интерпретация. Т. 10. № 16. С. 70-80. DOI: 10.19181/inter.2018.16.6

Люшер, М. (2003) Какого цвета Ваша жизнь. Закон гармонии в нас : практическое руководство. М. : Гиппо. 252 с.

Новгородова, Е. Ф. (2017) Особенности субъективного благополучия обладателей татуировок // Молодой ученый. № 15 (149). C. 536-540. URL: https:// moluch.ru/archive/149/42078/ [архивировано в WaybackMachine] (дата обращения: 21.02.2020). 
Овсянникова, О. А. (2017) Татуировка как социокультурное явление [Электронный ресурс] // Наука. Общество. Государство. № 1 (17). URL: https: //esj.pnzgu.ru/files/esj.pnzgu.ru/ovsyannikova_oa_17_1_25.pdf [архивировано в WaybackMachine] (дата обращения: 21.02.2020).

Скорова, О.В.(б/д) Психологические аспекта татуировки [Электронный pecypc] // Сайт психолога Скоровой Ольги Ивановны. URL: http://www. skorova.spb.ru/?mode=articles tattoo [архивировано в WaybackMachine] (дата обращения: 21.02.2020).

Федорова, А. А., Жукова, К. В. (2020) Личностные особенности лиц юношеского возраста, имеющих татуировки [Электронный ресурс] // Молодой ученый. № 2. С. 220-223. URL: https://moluch.ru/archive/292/66252/ [архивировано в WaybackMachine] (дата обращения: 21.02.2020).

Филатова, С. В. (2013) Энциклопедия татуировок. М. : РИПОЛ классик. 556, [1] c.

Шапарь, В. Б. (2016) Занимательная психология. Ростов-на-Дону : Феникс. $431 \mathrm{c.}$

Шнырева, О. А. (2009) Татуировка как социальное письмо // Вестник Удмуртского университета. Серия: Философия. Психология. Педагогика. Вып. 1. C. $103-106$.

Allan, P. (2016) These are the most tattoo-friendly companies to work for in the U.S. [Электронный ресурс] // Lifehacker. January 31. URL: https://lifehacker. com/these-are-the-most-tattoo-friendly-companies-to-work-fo-1755827988 [архивировано в WaybackMachine] (дата обращения: 21.02.2020).

Atkinson, M. (2004) Tattooing and civilizing processes: Body modification as self-control // Canadian Review of Sociology. Vol. 41. No. 2. P. 125-146. DOI: 10.1111/j.1755-618X.2004.tb02173.x

Broussard, K. A., Harton, H. C. (2017) Tattoo or taboo? Tattoo stigma and negative attitudes toward tattooed individuals // The Journal of Social Psychology. Vol. 158. Issue 5. P. 521-540. DOI: 10.1080/00224545.2017.1373622

Caplan, J. (2002) Bodies of inscription: A cultural history of the modern tattoo community [Review of: DeMello, M. Bodies of inscription: A cultural history of the modern tattoo community. Durham, N.C.: Duke U. Pr., 2000] // Historian. Vol. 64. No. 2. P. 406-407.

Degelman, D., Price, N. D. (2002) Tattoos and ratings of personal characteristics // Psychological Reports. Vol. 90. Issue 2. P. 507-514. DOI: 10.2466/pr0. $\underline{2002.90 .2 .507}$

Farrell, K. (2015) The psychology of abandon: Berserk style in American culture. Amherst, MA : Levellers Press. xii, 234 p.

Mehta, V. (2018) Are people with tattoos stigmatized? [Электронный pecypc] // Psychology Today. September 28. URL: https://www.psychologytoday. 
com/us/blog/head-games/201809/are-people-tattoos-stigmatized (дата обращения: 21.02.2020).

Naudé, L., Jordaan, J., Bergh, L. (2019) "My body is my journal, and my tattoos are my story": South African psychology students' reflections on tattoo practices // Current Psychology. Vol. 38. Issue 1. P. 177-186. DOI: 10.1007/s12144$\underline{017-9603-y}$

Neuhaus, C. (2018) Why tattoos are so popular [Электронный pecypc] // The Saturday Evening Post. February 27. URL: https:/www.saturdayeveningpost.com/ 2018/02/why-tattoos-are-so-popular/ [архивировано в WaybackMachine] (дата обращения: 21.02.2020).

Saleh, N. (2016) The true cost of a tattoo [Электронный ресурс] // Psychology Today. July 24. URL: https://www.psychologytoday.com/us/blog/the-red-lightdistrict/201607/the-true-cost-tattoo (дата обращения: 21.02.2020).

Дата поступления: 5.03.2020 г.

\section{REFERENCES}

Beketova, E. S. (2016) Vyiavlenie lichnostnoi problematiki sub"ekta sredstvami glubinno-psikhologicheskogo analiza tatuirovok [Identification of personal problem of subject by means of depth psychological analysis of tattoos]. Gumanitarnopedagogicheskoe obrazovanie, vol. 2, no. 2, pp. 10-15. (In Russ.).

Borokhov, A. D. (2011) Znachenie tatuirovok v diagnostike psikhicheskikh i povedencheskikh rasstroistv [Value of tattoos in the diagnosis of mental and behavioral disorders]. Meditsinskaia sestra, no. 7, pp. 24-32. (In Russ.).

Borokhov, A. D. (2018) Mnogoosevaia klassifikatsiia tatuirovok dlia integral'noi otsenki proiavlenii psikhopatologii lichnosti nositelia. Chast' 2 [Multi-axis classification of tattoos for an integrated assessment of the manifestations of psychopathology of the personality of the bearer. Part 2]. Meditsinskaia psikhologiia $v$ Rossii, vol. 10, no. 3 (50), pp. 10. (In Russ.). DOI: 10.24411/2219-8245-2018-13100

Vorobiyova, E. S. (2016a) Tatuirovanie kak ob"ekt sotsiologicheskogo issledovaniia [Tattooing as an object of sociological research]. Zhurnal sotsiologii i sotsial'noi antropologii, vol. 19, no. 3, pp. 148-161. [online] Available at: https:// cyberleninka.ru/article/n/tatuirovanie-kak-obekt-sotsiologicheskogo-issledovaniya (accessed 21.02.2020). (In Russ.).

Vorobiyova, E. S. (2016b) Formirovanie motivatsii k tatuirovaniiu kak mekhanizm konstruirovaniia identichnosti [Development of motivation to tattooing as a mechanism of identity construction]. Teoriia i praktika obshchestvennogo razvitiia, no. 6. [online] Available at: http://teoria-practica.ru/rus/files/arhiv_zhurnala/2016/6/ sociology/vorobiyova.pdf [archived in WaybackMachine] (accessed 21.02.2020). (In Russ.). 
Vorobiyova, E. S. (2018) O chem rasskazyvaet tatuirovannoe telo: gendernyi aspekt $\mathrm{v}$ opyte vizual'noi sotsiologii [What the tattooed body tells: The gender aspect in the experience of visual sociology]. Interaktsiia. Interv'iu. Interpretatsiia, vol. 10, no. 16, pp. 70-80. (In Russ.). DOI: 10.19181/inter.2018.16.6

Lüscher, M. (2003) Kakogo tsveta Vasha zhizn'. Zakon garmonii v nas [What color is your life. The law of harmony in us / Das Harmoniegesetz in uns] : A practical guide. Moscow : Hippo Publ. 252 s. (In Russ.).

Novgorodova, E. F. (2017) Osobennosti sub"ektivnogo blagopoluchiia obladatelei tatuirovok [Features of the subjective well-being of tattoo owners]. Molodoi uchenyi, no. 15 (149), pp. 536-540. [online] Available at: https://moluch.ru/archive/149/42078/ [archived in WaybackMachine] (accessed 21.02.2020). (In Russ.).

Ovsiannikova, O. A. (2017) Tatuirovka kak sotsiokul'turnoe iavlenie [Tattoo as a sociocultural phenomenon]. Nauka. Obshchestvo. Gosudarstvo, no. 1 (17). [online] Available at: https://esj.pnzgu.ru/files/esj.pnzgu.ru/ovsyannikova_oa_17_1 25.pdf [archived in WaybackMachine] (accessed 21.02.2020). (In Russ.).

Skorova, O. V. (s.d.) Psikhologicheskie aspekta tatuirovki [Psychological aspects of tattoo]. Sait psikhologa Skorovoi Ol'gi Ivanovny [Website of the psychologist Olga Ivanovna Skorova]. [online] Available at: http://www.skorova.spb.ru/ ?mode $=$ articles tattoo [archived in WaybackMachine] (accessed 21.02.2020). (In Russ.).

Fedorova, A. A. and Zhukova, K. V. (2020) Lichnostnye osobennosti lits iunosheskogo vozrasta, imeiushchikh tatuirovki [Personal characteristics of young people with tattoos]. Molodoi uchenyi, no. 2, pp. 220-223. [online] Available at: https://moluch.ru/archive/292/66252/ [archived in WaybackMachine] (accessed 21.02.2020). (In Russ.).

Filatova, S. V. (2013) Entsiklopediia tatuirovok [Encyclopedia of tattoos]. Moscow : RIPOL klassik Publ. 556, [1] p. (In Russ.).

Shapar, V. B. (2016) Zanimatel'naia psikhologiia [Recreational psychology]. Rostov-on-Don : Feniks Publ. 431 p. (In Russ.).

Shnyreva, O. A. (2009) Tatuirovka kak sotsial'noe pis'mo [Tattoo as a social message]. Vestnik Udmurtskogo universiteta. Seriia: Filosofiia. Psikhologiia. Pedagogika, issue 1, pp. 103-106. (In Russ.).

Allan, P. (2016) These are the most tattoo-friendly companies to work for in the U.S. Lifehacker, January 31. [online] Available at: https://lifehacker.com/theseare-the-most-tattoo-friendly-companies-to-work-fo-1755827988 [archived in WaybackMachine] (accessed 21.02.2020).

Atkinson, M. (2004) Tattooing and civilizing processes: Body modification as self-control. Canadian Review of Sociology, vol. 41, no. 2, pp. 125-146. DOI: 10.1111/j.1755-618X.2004.tb02173.x 
Broussard, K. A. and Harton, H. C. (2017) Tattoo or taboo? Tattoo stigma and negative attitudes toward tattooed individuals. The Journal of Social Psychology, vol. 158, issue 5, pp. 521-540. DOI: 10.1080/00224545.2017.1373622

Caplan, J. (2002) Bodies of inscription: A cultural history of the modern tattoo community [Review of: DeMello, M. Bodies of inscription: A cultural history of the modern tattoo community. Durham, N.C.: Duke U. Pr., 2000]. Historian, vol. 64, no. 2, pp. 406-407.

Degelman, D. and Price, N. D. (2002) Tattoos and ratings of personal characteristics. Psychological Reports, vol. 90, issue 2, pp. 507-514. DOI: $10.2466 /$ pr0.2002.90.2.507

Farrell, K. (2015) The psychology of abandon: Berserk style in American culture. Amherst, MA : Levellers Press. xii, 234 p.

Mehta, V. (2018) Are people with tattoos stigmatized? Psychology Today, September 28. [online] Available at: https://www.psychologytoday.com/us/blog/ head-games/201809/are-people-tattoos-stigmatized (accessed 21.02.2020).

Naudé, L., Jordaan, J. and Bergh, L. (2019) "My body is my journal, and my tattoos are my story": South African psychology students' reflections on tattoo practices. Current Psychology, vol. 38, issue 1, pp. 177-186. DOI: 10.1007/s12144-0179603-y

Neuhaus, C. (2018) Why tattoos are so popular. The Saturday Evening Post, February 27. [online] Available at: https://www.saturdayeveningpost.com/2018/02/ why-tattoos-are-so-popular/ [archived in WaybackMachine] (accessed 21.02.2020). Saleh, N. (2016) The true cost of a tattoo. Psychology Today, July 24. [online] Available at: https://www.psychologytoday.com/us/blog/the-red-light-district/2016 07/the-true-cost-tattoo (accessed 21.02.2020).

Submission date: 5.03.2020.

Иванова Лилия Андреевна — преподаватель ЧУ ДПО «Институт косметологии, эстетической медицины и визажного искусства - Дом русской косметики». Адрес: 115184, Россия, г. Москва, Большая Татарская ул., д. 35с3. Тел.: +7 (977) 729-81-57. Эл. почта: ivanovaliliya2013@yandex.ru

Ivanova Lilia Andreevna, Reader, Institute of Cosmetology, Aesthetic Medicine and Makeup Art - House of Russian Cosmetics. Postal address: 35c3 Bolshaya Tatarskaya St., 115184 Moscow, Russian Federation. Tel.: +7 (977) 729-81-57. Email: ivanovaliliya2013@yandex.ru 
Владимирова Диана Дмитриевна - бакалавр (педагог иностранных языков), выпускница Московского педагогического государственного университета. Адрес: 119991, Россия, г. Москва, ул. Малая Пироговская, д. 1, стр. 1. Тел.: +7 (916) 840-17-92. Эл. почта: dianochca1994@gmail.com

Vladimirova Diana Dmitrievna, Bachelor (teacher of foreign languages), alumna, Moscow State Pedagogical University. Postal address: Bldg. 1, 1 Malaya Pirogovskaya St., 119991 Moscow, Russian Federation. Tel.: +7 (916) 840-17-92. E-mail: dianochca1994@gmail.com

\section{Для ичитирования:}

Иванова Л. А., Владимирова Д. Д. Татуировка. Психологический анализ [Электронный ресурс] // Горизонты гуманитарного знания. 2020. № 2. С. 88101. URL: http://journals.mosgu.ru/ggz/article/view/1196 (дата обращения: дд. мм.гггг). DOI: $10.17805 /$ ggz.2020.2.6 